\title{
THE PROSPECTS AND CONSTRAINTS OF INTEGRATING SOCIAL MEDIA INTO THE NIGERIAN HIGHER EDUCATIONAL SYSTEM: STUDENTS' AND LECTURERS' PERSPECTIVES
}

\author{
Kwase Audu DOGARI \\ ORCID: 0000-0002-2092-0328 \\ Department of Mass Communication \\ Taraba State University \\ Jalingo, Nigeria \\ Oberiri Destiny APUKE \\ ORCID: 0000-0002-7657-4858 \\ Department of Mass Communication \\ Taraba State University \\ Jalingo, Nigeria
}

Received: 08/05/2018 Accepted: 24/07/2018

\section{ABSTRACT}

The discussion and debate on integrating social media into the formal education remain largely speculative rather than well informed and certain. Only limited studies and mainly from developed nations attempted to describe specific learning gains and benefits of social media as a formal tool in the learning environment. Studies that attempt to understand students and lecturers' perspective regarding integrating social media in the formal educational setting are even in their embryonic phase. This paper reports students' and lecturers' perspectives on the formal integration of social media platforms into the Nigerian university educational system. The study took a qualitative approach based on online audience discussion with lecturers and students at a large public university in Eastern Nigeria. Results reveal that social media has become very popular among students and might be valuable instruments for teaching as they promote collaborative and cooperative learning among students and lecturers. Yet, issues of security, poor network, distractive tendencies, and addiction beyond academic walls pose challenges to social media use in higher education.

Keywords: Collaborative and cooperative learning, social media, students, University educational system, university lecturers.

\section{INTRODUCTION}

In recent decades, evidence has indicated that the growth of Information Communication Technologies (ICTs) has transformed the ways society conducts business, training, communication among others. More so, the emergence of social media as another platform on the internet has gained massive popularity, especially among youth (Poushter et al., 2015). This means that there has been explosive growth in the number and usage of social media websites like Facebook, Twitter, YouTube and WhatsApp among young people globally. In view of this, Prensky (2001) classified people into Net Generation, I Generation and X Generation. "Net Generation" are those born between 1980 and 1989, "I Generation" refers to those born between 1990 and 1999 while "Generation X" are those born between 1965 and 1979. Uniform with this notion, research has revealed that an average undergraduate student in Nigeria is within the age of 18-30 (Adum, Ekwugha, Ojiakor, \& Ebeze, 2016; Shadrach, 2016; Anasi, 2006; Ani, 2010). This indicates that 
students in universities across Nigeria fall into the "Net" and "I" Generations. To Prensky, these generations function best when networked (2001, p. 2).

Based on this idea, it is logical to suggest that in order for university education in Nigeria to be effective there is the need to integrate social media like Facebook, WhatsApp, Twitter and YouTube into their learning environment. Concretising this notion, Stanciu, Mihai, and Aleca (2012) held that due to the continuous gain of using new communication technologies among students in routine life, the implementation of these technologies in learning activities becomes a requirement. Moreover, there has been an emphasis on the role that technology can play in harnessing effective learning. Therefore, e-learning principles have attracted the attention of the university's management around the world (Shadrach, 2016; Ani, 2010). The provision of internet connection and corresponding technologies like projectors, desktops/laptops, and some software was discovered in many Nigerian schools as lecturers were also educated in the usage of these gadgets (Anasi, 2006).

In addition, Stanciu et al. (2012) observed that "the technology savvy students of this decade not only anticipate the role of social media, they seek it out... educators need to become as savvy as their students". As such, higher education teaching practices have evolved over the last twenty years, with more emphasis on student-centred pedagogy or interactive learning. Thus, despite word limitation and geographical distance, social network sites have been utilized to bridge communication and connections among teachers and students, as well as build rapport through encouraging discussions (Kehrwald, 2007). Various surveys have confirmed that teachers/lecturers are now utilising social networking technologies for teaching and learning which is transforming informal learning into formal learning (Manan et al., 2012; Veletsianos and Navarrete, 2012; George, 2011). This means that social networking activities have the possibility of enhancing student contact as well as improve their participation in class. Introverted students who are not able to raise questions before peers at school could engage themselves in online group learning with less or no anxiety attached (Wheeler et al., 2008). Indeed, integrating social media into the students' learning process offers them with an opportunity to assume control of their learning activities, which in turn promote their confidence (Yunus, Salehi, \& Chenzi, 2012). This student-centred learning approach is what is changing the culture of many of today's learning classrooms. Thus, Social media such as Facebook, Twitter, Whatsapp, YouTube, and Skype has improved communication and learning process because a large number of social technologies provided on the internet are free or require a little accessing fee which has encouraged wider utilisation and adoption (Brown, 2010). Intrinsically, through the internet, students can form their own page, access news as well as lecture notes from an email sent by lecturers.

Nevertheless, the question is - how social media can be driven into formal education considering the fact that the media have been subject to much debate within the educational community. Some investigators maintained that social media utilisation affects students' academic accomplishments as they waste too much time on them, and as such compromise and disrupt the young people's involvement with "traditional" education provision (Musa et al., 2015; Yoo \& Kim, 2013; Kirschner \& Karpinski, 2010). However, other studies conclude that the academic performance of the students was not affected by the use of social media and that its usage helps in (re) engaging learners with their studies (Alwagait et al., 2015; Mbodila et al., 2014; Tamirat \& Molly, 2014). Despite these mixed findings, it is important to note that social media are consistently being adopted by students. Certainly, there is a body of literature that supports informal learning via social media, and as such sharing of ideas, providing peer feedback, and engage in critical thinking has been identified as the gratification derived from using social media in the learning process (Selwyn, 2009). Substantiating this view, similar surveys have also reported four main benefits of social media employment in higher education to include, enhancing the relationship, improving learning motivation, offering personalised course material and developing collaborative abilities (Chugh \& Ruhi, 2017; Dumpit \& Fernandez, 2017; Selwyn, 2012). 
Yet, evidence from these studies shows that the discussion and debate on integrating social media in formal education remain largely speculative rather than well informed and certain. Only limited studies and mainly from developed nations attempted to describe specific learning gains and benefits from social media as a formal tool in the learning environment. For example, in Nigeria, studies about social media only focused on the usage pattern, the purpose of use, type of social media use, challenges of use and time spent on the media. Others focused on identity and privacy topics. Drawing from this, it is evident that there exists a gap in the literature regarding social media and university education in the country. More so, studies that attempt to understand students and lecturers' perspective regarding integrating social media in the formal educational setting are even in their embryonic phase. Against this backdrop, this present study examines students and lecturer's perception on how social media can be integrated into the university education system in Nigeria. Specifically, it looks into the potential benefits and challenges social media may present if being infused formally into the educational context.

\section{REVIEW OF THE LITERATURE}

This section discusses the concept of social media, it further demonstrates previous empirical studies on the role of social media in the educational settings, and then concludes with the theoretical framework. The rationale for explicating the concept of social media is because social media have received an array of explanation, thus, it is appropriate to clarify it as applied in the context of this current research.

\section{The Concept of Social Media}

Given the dynamic nature and the complexity of the term social media, it becomes quite difficult to define. However, scholars of different background made several attempts. For example, Bryer and Zavatarro (2011) define social media as "... technologies that facilitate social interaction, make possible collaboration, and enable deliberation across stakeholders". Similarly, Kaplan and Haenlein (2010) defined social media as "a group of Internet-based applications, build on the ideological and technical foundations of Web 2.0, and that allow the creation and exchange of user-generated content". Elaborating these definitions, Nwangwa, Yonlonfoun and Omotere (2014) describe social media as online applications for social networking sites, social bookmarking and sharing tools, social citation tools, blogging and microblogging tools, practical worlds, e-conference presentation sharing tools, audio and picture tools, e-project management tools, and research and writing collaboration tools; primarily developed to foster user-centred social interaction.

In line with these submissions, social media can be described as a range of online platforms and applications, which allow users to communicate, collaborate, interact, and share data. So, social media is about transforming monologue into dialogue and about transforming Internet users from mere readers to creators of content. These media are in many different forms like Wikipedia, Blogs (Blogger, TypePad and WordPress, etc.); Microblogs (e.g. Twitter, Friend Feed); Media Sharing Sites (Video and Photo) such as YouTube and Flickr; Social networking websites such as Facebook, Google+ and LinkedIn and lastly RSS (Kaplan \& Haenlein, 2010). However, social networks and messengers like Facebook, Twitter, Whatsapp, and YouTube are popular and used among students and academics.

\section{Empirical Review}

In recent years, there has been an array of an investigation into social media as tools for teaching, learning and research. For example, Lockyer and Patterson (2008) conducted a longitudinal study that used an experimental approach to examine social media and experience in a formal education context among postgraduate students and lecturers in Regional Australian University during the 2007 academic year. Participants reported the potential of social media to provide deeper engagement in the topic or subject, but also identified difficulties in using Flickr website. Overall, this experience of using a social networking site 
in a formal education environment realized positive learning outcomes and experiences for the participants, but poses such challenges related to literacy level among teachers and learners. In the same vein, Hazari, North, and Moreland (2009) conducted an exploratory study to investigate the potential of Wiki technology as a tool for teaching and learning. The results establish that Wiki technology provides an opportunity to develop pedagogically effective learning environments, but the study fails to show how such can be actualized and the likely challenges Wiki technology may pose in a learning environment.

Uniform with this study, Shen and Eder (2009) likewise surveyed students' intentions to employ the virtual world Second Life for teaching and explores factors related to their aims. "Second Life is a three dimensional (3D) electronic environment where members can socialize, hold virtual meetings, or conduct economic transactions. Results suggest that perceived ease of use affects user's intention to adopt SL and Computer self-efficacy and computer playfulness are significant antecedents of perceived ease of use of virtual worlds. This means that the perceived advantages and simplicity of new media technology is a motivation for the consolidation of the media in a higher education environment. These results are coherent with a study by Wang and Braman (2009) who used series of field trials of the integration of Second Life in an introductory computer course. The study found that the integration of Second Life activities improved students' learning experience. Furthermore, students participated in the Second Life activities in the case study showed higher learning motivation and better performance.

Another study by Li and Pitts (2009) investigated the use of virtual office hours as a medium for students to communicate with their professors using Facebook and Instant messaging (IM) Apps. The findings advocate that students' use of virtual office hours is not significantly different from their use of traditional office hours; however, participants in classes that offered virtual office hours reported higher levels of satisfaction with office hours than students in classes that offered only traditional face-to-face office hours. Implicatively, the study shows insight into some benefits of integrating social media in the formal learning environment. Additionally, Selwyn (2009) presents an in-depth qualitative analysis of the "Facebook," "wall" activity of 909 undergraduate students in a UK university. Analysis of these data shows how much of students' education-related use of this social networking application was based around either the "post-hoc" critiquing of learning experiences and events, the exchange of logistical or factual information about teaching and assessment requirements. Others are supplication and moral support about assessment or learning, or the promotion of oneself as academically incompetent and/or disengaged. With these themes in mind, the paper concludes that rather than necessarily enhancing or eroding students' "front-stage" engagement with their formal studies, Facebook users must be seen as being situated within the "identity politics" of being a student. In particular, "Facebook" appears to provide a ready space where the "role conflict" that students often experience in their relationships with university work, teaching staff, academic conventions and expectations can be worked through in a relatively closed "backstage" area.

Similarly, Junco, Heiberger and Loken (2011) carried out a semester-long experimental study in South Dakota State University, to determine if using Twitter for educationally relevant purposes can affect college student engagement and grades. The results divulged that the experimental group had a significantly greater increase in engagement than the control group, as well as higher semester grade point averages. Analyses of Twitter communications showed that students and faculty were both highly engaged in the learning process in ways that transcended traditional classroom activities. This study provides experimental evidence that Twitter can be used as an educational tool to help engage students and to mobilize faculty into a more active and participatory role.

In the same vein, Irwin, Ball and Desbrow (2012) examined students' perceptions of using 'Facebook pages' within Griffith University and University of Queensland. The study revealed that most students $(\mathrm{n}=135$, $78.0 \%)$ anticipated that a Facebook page would facilitate their learning, by increased interaction with other 
students and instructors, and notifications for course information. However, perceptions of the effectiveness of the page as a learning tool were variable, with only $51 \%$ of students stating that it was effective. Despite this, the majority of students $(\mathrm{n}=110,76.4 \%)$ recommended using Facebook in future classes. Corroborating these findings, Stanciu et al. (2012) concludes that social networking websites have become very popular among students and might be seen equally valuable instruments for teaching. By implication, these studies suggest that social media has the potential to promote collaborative and cooperative learning and opens a wide perspective on students' availability to use social networking sites but fail to adequately show how such technologies can be integrated.

A similar study by Allen and Nelson (2013) used a qualitative case study on integrating social media in an online graduate youth development course at North Carolina State University, United State of America. Results designate that although few students enrolled with strong technology skills, they left with new abilities and strong attitudes about the importance of using social media in their professional roles. This reinforces the fact that students are interested and willing to learn new skills and ideas as long as social media are adopted as learning tools. Consistent with this view, Roebuck and Siha (2013) carried a survey on the perceptual experiences of professors using social media in the schoolroom. It was found that Professors, regardless of sex or rank, held statistically the same views of the advantages as well as the concerns related to social media usage in the classroom. The advantages include student feedback from multiple sources, more engaged students, information sharing, stronger classroom community, higher quality student collaborative work, discussion opportunities, improved creativity, and prepare for the work environment. While the concerns shared by the respondents include monitoring, liability, a need for institutional approach, an overabundance of information, and time intensive. This finding proves valuable to this current study as it improves the consensus regarding the advantages and concerns of using social media in the classroom.

In other related investigation, Holotescu, Grosseck, and Cretu (2013) considered how Romanian higher education actors currently perceive and utilise social media. Findings revealed an increasing use of social media by educational actors in Romania but only a few universities have adopted coherent strategies and policies for the academic integration of social media and develop better methods for teaching and learning based on these strategies. This implies a need for a further inquiry like this current research. In other related work, Dunn (2014) explored the concept of interactive learning by focusing on a specific use of mobile and portable technology among students of the University of Glasgow. The college-wide survey indicated that $68 \%$ thought social media could enhance their learning experience. $22 \%$ indicated that it would not add any value or would cause a distraction, whilst $10 \%$ were unsure. The evidence points towards the need for further inquiry.

As established in the reviewed investigations of this present study, there is a volume of works already conducted on the use of social media technologies in higher education, studies up to this point have not make detail explanation on how social media technologies can be adopted into university formal education system in developing countries. This implies that almost all the studies that attempted to examine social media as a tool for educational intervention are from developed nations with wider forms of social media, powerful network service, better economy and literacy level compared to Africa and Nigeria in particular. Thus, depending on the findings of these studies and implementing them in Nigeria system may not yield needed results. Therefore, there is a need to domesticate such studies to fit into the Nigerian education landscape scenario. In line with this view, this current study serves to make an effort toward actualizing these noted gaps by using primary data from academics and students to examine the relevance and ways social media can be integrated into university education in Nigeria. 


\section{Theoretical Underpinning}

This present study is focused on Technology Acceptance Model (TAM). The theory was propounded by Fred Davis in 1986 to explain why people accept or reject particular technology (Park, 2009). According to Venkatesh and Davis (2000), there are two factors that may lead to adoption or rejection of any new technological innovation. These factors are "perceived usefulness of the technology" and "ease of use of the technology". Perceived usefulness (PU) is the degree to which a person believes that using a particular device would enhance his or her job performance, while perceived ease-of-use (PEOU) is the degree to which a person believes that using a particular device would be free from effort or has less effort.

TAM has been widely criticized, leading to extended versions of the model called TAM 2 (Davis, Bagozzi, $\&$ Warshaw, 1989). The model is said to have limited explanatory and predictive power, triviality, and lack of any practical value (Chuttur, 2009). Furthermore, Benbasat and Barki (2007) argue that TAM "has diverted researchers' attention away from other important research issues and has created an illusion of progress in knowledge accumulation".

Despite the criticism above, the model (TAM) remains relevant in explaining technology adoption and/or employment. This is because the theory encompasses elements from theories like Uses and Gratification (Katz, Blumler, \& Gurevitch, 1974), and ACE (accessibility, control and excitement) model (Wu, Tao \& Yang, 2008) which are established theories often use to explain the use of technology. Additionally, Lee, Cheung, and Chen (2005) suggested that TAM is a solid and valid theoretical model to apply in explaining the use of technology among students. It is based on this premise that the model fits into this current study. Hence, the perceived usefulness of integrating social media into university education as well as the perceived easiness of the media such as portability, flexibility, affordability and interactivity will be brought to the fore.

\section{METHODOLOGY}

\section{Research Design}

This study used a qualitative case study research methodology (Stake, 2013) because it was felt necessary to develop a context-based understanding of the individual experiences of the participating students and lecturers. The present study employed a range of sources of information to include, online questionnaire interviews and group discussion. The online interview was adopted because of easy access to respondents, convenience and time-saving. In keeping with the general practice of qualitative research, the participants were promised and given anonymity in order to encourage them to discuss pertinent issues in depth and in detail (Kontagora, Watts, \& Allsop, 2018).

\section{Participants/Sampling Process}

The sample group for this study were twelve $(\mathrm{n}=12) \quad$ lecturers and twenty-six $(\mathrm{n}=26)$ registered masters students of Mass communication, in one large public University in Eastern Nigeria. The researchers adopted purposive and convenience sampling technique to choose the participants. The selection criteria were based merely on those who acknowledged at the initial encounter that they regularly use social media as well as willing to participate in the investigation. Indeed, selecting those who frequently use the social media will provide a better understanding of the areas social media improves students' educational pursuit as well as the challenges impeding the actual utilization of social media in the educational context. It was also observed at the time of this study, some participants were not willing to partake in the study due to reasons that are best known to them; hence, the authors conveniently selected the participants that were available.

Therefore, the twelve lecturers (i.e. 8 males and 4 females) were purposefully sent items (questionnaires) via email to elicit information about their attitudes and feelings regarding social media as a formal tool of learning in the university set up. Likewise, items, soliciting information from the students regarding their opinions about social media as a formal tool of university education were posted into a WhatsApp group 
chat of masters' students of the 2015/2016 set, and the students were asked to respond accordingly. Nineteen (19) out of the twenty-six (26) registered students and members of the group chat responded. Specifically, the participants were asked:

$>$ If they use social media in their educational settings.

$>$ The ways in which social media could be integrated into the university education.

$>$ The benefits of integrating social media into the university education.

$>$ The challenges of adopting social media in the educational settings.

All responses were carefully monitored over a period of 12 weeks and then coded into three themes, to include ways of integrating social media into university education, the benefits of adopting social media in university education and challenges of the adoptions of social media in university education. These accounts were then thematically analysed which is coherent with the method adopted in similar prior studies (Parajuli \& Doneys, 2017; Braun \& Clarke, 2006).

\section{RESULTS AND DISCUSSION}

\section{Integrating Social Mediai into University Education}

It was discovered that social media are powerful tools that can be used to share relevant course materials. One of the academic participants commented:

Links, photos or multimedia content related to specific subjects can be made available to students within seconds through social media.

He added,

Social media tools can be used to share resources, promote brainstorming, extend the class discussion, and promote student sense of community. For example, students could be assigned to create their own customized reading lists on a particular topic. An educator may use Twitter to create and update their class reading or news lists. Interestingly, social media gives the lecturer the opportunities to share every form of the message, be it video, audio, written text, animation and images. With YouTube, for instance, a lecturer can create a succinct and powerful video presentation and send it to students to watch and learn from it, especially when the lecturer is not around or is out of the county. Thus, with social media, a plethora of useful contents and links to relevant material like posting bibliographical notes or hyperlink is possible.

Supporting this view, another lecturer state:

As an academic tool, social media can a be used to enhance online studies where people take classes without practically or physically meeting under one rooj. In addition, another lecturer commented that social media can be used to track and study feedbacks about particular subjects or class, the area of difficulty, delivery style among others. With such feedbacks, the lecturer will improve delivery as well as clarify difficult concepts by providing additional examples.

These findings are in harmony with past research by Lockyer and Patterson (2008) which reported that the potential of social media in education include providing deeper engagement in the topic or subject. The same study concluded that the experience of using a social networking site in a formal educational environment leads to positive learning outcomes and experiences for the teachers and learners.

In this present study, it was discovered that most of the students that contributed to the online discussion, explain that social media can be used in publishing news on lecture schedules, tests, exams and seminar among others. The media can also be used in tracking news about books, journals or treaties available in the libraries within and outside the school. A student puts it this way: 
WhatsApp group chat remains the best channel for informing classmates about all that need to be known. On such platform, the message gets fast and since most students always log to their Whatsapp, the message gets to almost all at very cheap cost. To me, a class without an official Whatsapp group chat will have an information crisis.

Furthermore, the students identified social media as the ideal venue for a meeting to discuss issues bothering the class while everyone is in his or her comfort making a useful contribution. The students claimed that the integration of social media into the Nigerian educational system will be vital because of its usefulness and easiness in usage. This view is consistent with the notion of the TAM model which suggest that perceived usefulness (PU) which is the degree to which a person believes that using a particular device would enhance his or her job performance, and perceived ease-of-use (PEOU) which is the believe that using a particular device would be free from effort or has less effort are the major reasons why people adopt certain technological devices. Therefore, it could be deduced that integrating social media into the Nigerian educational system may be beneficial to its growth and development at large.

\section{The Benefits of Adopting Social Media in University Education}

One of the major advantages of social media tools, which has been reported many times in research, is the creation of community. Social media fosters communication, engagement, and collaboration (Harris \& Rea, 2009; Hung \& Yuen, 2010; Junco, Heiberger, \& Loken, 2011; Wankel, 2009). A community can be created locally for a particular class, beyond the boundary of a single classroom, for the university, or even beyond the campus using a virtual world. Hence, the use of social media tools complements face-to-face classes and enhance learning and engagement, particularly among students. While some introverted students may find it difficult to participate in face-to-face classes, they may be more comfortable posting comments and thoughts to special groups on Facebook or any other social medium (Wheeler et al., 2008). It was observed from the data generated that most lecturers are sceptical about the benefit of social media integration in university education, unlike the students. This observation is similar to Stanciu et al. (2012) who concludes that social networking sites have become very popular among students and might be considered as valuable tools for education. The same survey stated that social media has the potential to promote collaborative and cooperative learning and opens a wide perspective on students' availability to use social networking sites.

In this present study, most of the students claimed that social media is beneficial because they can gain access to the lecturer during off days or when dealing with lecturers that are not always accessible face-to-face. For example, a student maintained that:

Social media is a convenient way to interact with specific people and get the feedback quickly, also it is a more attractive approach which is welcomed by young people who live in the age of IT.... Social media, especially Twitter, is a valuable tool to use within Higher Education, it can enhance learning as students can be connected to tutors, and peers round the clock.

Another student explains that:

The use of social media in the university education will maximize time for both the lecturer and the students in general... the student will have the privilege to receive advice from the lecturer about personal challenge directly within a short time despite the distance.

Furthermore, it was revealed that the multiple forms of data that can be uploaded to social media would enhance students' level of comprehension of lectures. One of the academic concurs:

Using social networking sites allows sharing multimedia resources like photos, videos or hyperlinks to another web resource.

This suggests that one of the main advantages of using social network sites as a tool for education consists of a unique approach which involves collaborative group work and sharing of knowledge. Several studies 
(Ajjan \& Hartshorne, 2008; Lockyer \& Patterson, 2008) stress that social networking sites provide support for collaborative learning. Users of social networking sites can join study groups corresponding to a certain school, class or group they belong to and can share educational resources and knowledge in an easier way. Consistent with this notion, a similar research concludes that using social networking sites in everyday life (Mazman \& Usluel, 2010), coupled with the fact that most users spend a lot of their time online provides a good support in the context of education. This view is coherent with the comments of the students, which suggests that with social media, the student would have "store" to visit when in need of relevant material. According to them, even when you miss a lecture, with social media content and presentation uploaded online, you can log in and download at your convenience. Hence, the entire students concurred that they utilise social media because of its usefulness and ease of use. These findings are related to the (TAM) theory which suggests that the two factors that may lead to adoption or rejection of any new technological innovation is "perceived usefulness of the technology" and "ease of use of the technology". Perceived usefulness (PU) is the degree to which a person believes that using a particular device would enhance his or her job performance, while perceived ease-of-use (PEOU) is the degree to which a person believes that using a particular device would be free from effort or has less effort. It is clear that the students believe to a large degree that using social networking sites enhance their performance. As claimed by them it enhances learning as students can be connected to tutors, and peers round the clock.' In addition, the participants all believe that while using social networking sites there is less effort used.

\section{Challenges of Adoptions of Social Media in University Education}

From the data gathered in this study, both students and lecturers identify a series of challenges associated with social media as tools in teaching and learning in higher education, however, the lecturers who commented are more pessimistic on their views against social media than students. One of the lecturer's comment thus:

... I do not think that social media is a useful way in which to learn. It provides only superficial contact with peers/staff and can detract from essential skills which should be developed in Higher Education such as formal academic writing, verbal communication, self -awareness and reflection on the learning experience.

Another lecturer identified issue of information over-dose of social media, she states: With social media-like Whatsapp group chat, messages could become a source of spam because of excesses... many participants often forget the essence of the group by frequently posting irrelevant messages, photos among others. With this, many see social media as a distraction from any serious academic work.

Furthermore, another academic asserted:

The possible challenge with using social media in higher education will be access to social media by many students, the issue of literacy among lecturers and the epileptic nature of Nigerian network.

While the students that took part in the discussion concur that issue of the poor power supply and money for subscription remain a bane in using social media for the academic purpose. Other students revealed that issue of privacy and security is the greatest challenge that will bedevil the use of social media. One student puts it this way:

Many people don't like to make their details like phone numbers, names, location among others open online due to security reasons. It is possible that your detail can be retrieved from social media and use for fraudulent reasons, bully and blackmail... 
This supports the results of prior research which revealed that poor internet connectivity, receiving of unwanted messages/pictures and electricity failure was considered as the leading problems encountered while using social media. Similar studies have identified privacy and security as some of the challenges encountered in the use of social media (Apuke \& Ezeah, 2017; Brady, Holcomb, \& Smith 2010; Barnard, 2008). Affirming this impression, Ngonidzashe (2013) results demonstrated that the major challenges faced in the utilisation of social media by students in higher education were security and promotion of antisocial behaviour, exposure to inappropriate material, unwanted adult interactions as well as bullying from peers.

In this present study, the problem of addiction was also discovered to be a problem with the use of social media. For example, a student expressed that:

Using social media as an official tool will only reinforce the problem of computer addiction, which is already a problem for students.

This outcome is similar to the results of some investigators who maintained that social media utilisation affects students' academic skills as they waste too much time on them, and as such compromise and disrupt the young people's engagement with "traditional" education provision (Musa et al., 2015; Yoo \& Kim, 2013; Kirschner \& Karpinski, 2010).

\section{CONCLUDING REMARKS AND RECOMMENDATIONS}

The debate on integrating social media into the formal education remains largely speculative rather than well informed and certain. Only limited studies and mainly from developed nations attempted to describe specific learning gains and benefits of social media as a formal tool in the learning environment. Studies that attempt to understand students and lecturers' perspective regarding integrating social media in the formal educational setting are even in their embryonic phase. This paper reports students' and lecturers' perceptions of the formal integration of social media platforms into the Nigerian university educational system.

In a technology-driven world like ours, technology use in education is inevitable. Hence, social media as shown in this study has become very popular among students and might be valuable instruments for teaching as they promote collaborative and cooperative learning among students and lecturers. This notion is in harmony with a prior research which concludes that the potential of social media in education include providing deeper engagement in the topic or subject, and the experience of using a social networking site in a formal educational environment leads to positive learning outcomes and experiences for the teachers and learners (Lockyer \& Patterson, 2008).

The students in this study, believe to a large degree that using social networking sites enhance their performance. As claimed by them it enhances learning as students can be connected to tutors, and peers round the clock.' In addition, the students believe that while using social networking sites there is less effort used. These comments are related to the (TAM) theory which suggests that the two factors that may lead to adoption or rejection of any new technological innovation is "perceived usefulness of the technology" and "ease of use of the technology. Also, the entire participants believed that one of the main advantages of using social network sites as a tool for education consists of a unique approach which involves collaborative group work and sharing of knowledge. This view is in harmony with several prior studies (Ajjan \& Hartshorne, 2008; Lockyer \& Patterson, 2008) which stressed that social networking sites provide support for collaborative learning. 
Nevertheless, it was found that most of the lecturers that participated in this study were sceptical about the benefit of social media integration in the Nigerian university system. They claimed that issues of security, poor network, distractive tendencies, and addiction beyond academic walls pose challenges to social media use and integration in the Nigerian higher education. This notion was similarly identified by the sampled students. These results are similar to prior studies which revealed that poor internet connectivity, receiving of unwanted messages/pictures and electricity failure was considered as the leading problems encountered while using social media in the educational context (Apuke \& Ezeah, 2017). Other related research has also found privacy and security as some of the challenges encountered in the use of social media (Brady, Holcomb, \& Smith 2010; Barnard, 2008).

Conclusively, it could be deduced that the use of social media technologies like Facebook, Twitter and Whatsapp in a formal manner in Nigeria is still in its embryonic stage, even though it comes with some promises. What this connotes is that, as educators and students are encouraged to embrace social media networks to leverage engagement, enhance teaching and learning, appropriate caution and limitations need to be considered while researchers continue to investigate better ways in which tertiary institutions in Nigeria can adopt social media as tools in a learning environment with a minimum level of risks. Therefore, it is important to make some useful recommendations:

$>$ Social media platforms officially created for course purpose should be guided by certain rules that will regulate excessive posting of materials that are not needful especially among students.

$>$ The platforms should not be used for personal discussions. A student that wants to discuss a personal matter with a colleague or the lecturer should use personal inbox.

> Students should be taught how to regulate addiction to the computer (social media). This called fall on parents, teachers, media and guidance to brace up in their responsibility to their children.

$>$ The government should improve power supply as well as make legislation that will compel telecommunication companies to introduce cheaper data plan and stable network service affordable to students.

\section{BIODATA and CONTACT ADDRESSES of AUTHORS}

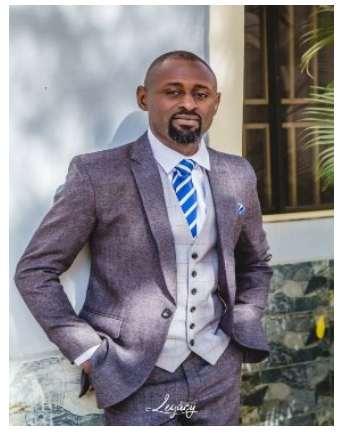

Kwase Audu DOGARI lectures in the Department of Mass Communication, Taraba State University Jalingo. He holds a B.Sc. (Second class upper). degree in Mass Communication from the Kwararafa University Wukari, Nigeria, a Professional Diploma in Education from the Ahmadu Bello University Zaria, and is currently rounding up his M.Sc. in Mass Communication at the Nnamdi Azikiwe University Awka, Nigeria. He has coauthored several articles in reputable journals within and outside Nigeria such as the Global Media Journal. His research interests include media and society, public relations and advertising and the new media.

Kwase Audu DOGARI

Department of Mass Communication, Faculty of Social and Management Sciences, Address: Taraba State University, PMB 1167, Jalingo, Nigeria

Phone: +2348036545358

E-mail: kwaseaudu@gmail.com 


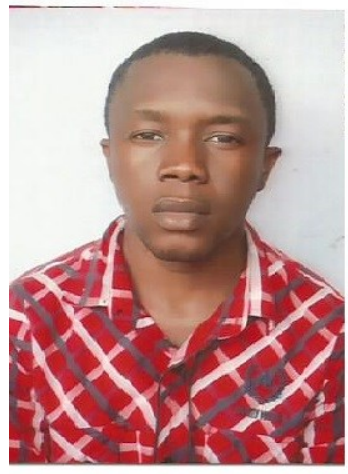

Oberiri Destiny APUKE, is a Lecturer in the Department of Mass Communication, Taraba State University, Jalingo, Nigeria. He obtained his masters at Master's degree in Communication Sciences at the European University of Lefke, North Cyprus. His research interest cuts across new media (i.e. the use of internet, social media and computer in education), gender studies, film/media studies, media ideology and representation, conflict and media studies, and most recently online/digital/citizen journalism. He has journal articles published in international indexes, a book and other national and international articles.

Oberiri Destiny APUKE

Department of Mass Communication,

Faculty of Social and Management Sciences,

Address: Taraba State University, PMB 1167, Jalingo, Nigeria.

Phone: +2347068851417

E-mail: apukedestiny@gmail.com

\section{REFERENCES}

Adum, A.N, Ekwugha, U.P, Ojiakor, O.E \& Ebeze, U.V. (2016). Screen time, health implications and university students' awareness in Nigeria. International Journal of Communication and Media Science, vol. 3 Issue 3 May to June.

Ajjan, H., \& Hartshorne, R. (2008). Investigating faculty decisions to adopt Web 2.0 technologies: Theory and empirical tests. The internet and higher education, 11 (2), 71-80.

Anasi, S. (2006). Internet use patterns of undergraduate students at the University of Lagos, Nigeria. University of Dares Salaam Library Journal, 8 (1), 1-15.

Ani, O. E. (2010). Internet access and use: A study of undergraduate students in three Nigerian universities. The Electronic Library, 28 (4), 555-567.

Apuke, O. D., \& Ezeah, G. H. (2017). The access and utilisation of social networking sites among social science students' in northeastern Nigerian public universities. International Journal of Social Sciences and Humanities Review, 7 (2).

Barnard, A. (2008). Myspace agrees to lead the fight to stop sex predators. New York Times, 1 (1), 1985.

Benbasat, I., \& Barki, H. (2007). Quo Vadis TAM?. Journal of the association for information systems, 8 (4), 7.

Blumler, J. G., \& Katz, E. (1974). The Uses of Mass Communications: Current Perspectives on Gratifications Research. Sage Annual Reviews of Communication Research, Volume III.

Brady, K. P., Holcomb, L. B., \& Smith, B. V. (2010). The use of alternative social networking sites in higher educational settings: A case study of the e-learning benefits of Ning in education. Journal of Interactive Online Learning, 9 (2).

Braun, V., \& Clarke, V. (2006). Using thematic analysis in psychology. Qualitative research in psychology, $3(2), 77-101$.

Bryer, T. A., \& Zavattaro, S. M. (2011). Social media and public administration: Theoretical dimensions and introduction to the symposium. Administrative Theory \& Praxis, 33 (3), 325-340. 
Chugh, R., \& Ruhi, U. (2017). Social media in higher education: A literature review on Facebook. Education and Information Technologies, 1-12.

Chuttur, M. Y. (2009). Overview of the technology acceptance model: Origins, developments and future directions. Working Papers on Information Systems, 9 (37), 9-37.

Davis, F. D., Bagozzi, R. P., \& Warshaw, P. R. (1989). User acceptance of computer technology: a comparison of two theoretical models. Management Science, 35(8), 982-1003.

Dumpit, D. Z., \& Fernandez, C. J. (2017). Analysis of the use of social media in Higher Education Institutions (HEIs) using the Technology Acceptance Model. International Journal of Educational Technology in Higher Education, 14 (1), 5.

Dunn, L. (2013). Teaching in higher education: can social media enhance the learning experience? In: 6th Annual University of Glasgow Learning and Teaching Conference, 19th Apr 2013, Glasgow, UK.

Harris, A. L., \& Rea, A. (2009). Web 2.0 and virtual world technologies: A growing impact on IS education. Journal of Information Systems Education, 20 (2), 137.

Harris, A., and A. Rea. (2009). Web 2.0 and Virtual World Technologies: A Growing Impact on IS Education." Journal of Information Systems Education 20 (2).

Hazari, S., North, A., \& Moreland, D. (2009). Investigating Pedagogical Value of Wiki Technology. Journal of Information Systems Education, 20 (2), 187-199.

Holotescu, C., Grosseck, G., \& Cretu, V. (2013, May). MOOC's Anatomy: Microblogging as the MOOC's Control Center. In the International Scientific Conference eLearning and Software for Education (Vol. 2, p. 312). "Carol I" National Defence University.

Hung, H. T., \& Yuen, S. C. Y. (2010). Educational use of social networking technology in higher education. Teaching in higher education, 15 (6), 703-714.

Irwin, C., Ball, L., Desbrow, B., \& Leveritt, M. (2012). Students' perceptions of using Facebook as an interactive learning resource at the university. Australasian Journal of Educational Technology, 28 (7).

Junco, R., Heiberger, G., Loken, E. (2011). The effect of Twitter on college student engagement and grades. Journal of Computer Assisted Learning, 27(2), 119-132.

Kaplan, A. M., \& Haenlein, M. (2010). Users of the world, unite! The challenges and opportunities of Social Media. Business Horizons, 53(1), 59-68.

Allen, K. and Nelson, D., (2013). Integrating Social Media in an Online Graduate Youth Development Course. Journal of Online Learning and Teaching, 9(4), p.566.

Kontagora, H.L., Watts, M. and Allsop, T. (2018). The management of Nigerian primary school teachers. International Journal of Educational Development, 59, pp.128-135.

Lee, M. K., Cheung, C. M., \& Chen, Z. (2005). Acceptance of Internet-based learning medium: the role of extrinsic and intrinsic motivation. Information \& Management, 42(8), 1095-1104.

Li, L., \& Pitts, J. P. (2009). Does It Really Matter? Using Virtual Office Hours to Enhance StudentFaculty Interaction. Journal of Information Systems Education, 20 (2), 175-185.

Lockyer, L. \& Patterson, J. (2008). Integrating social networking technologies in education: a case study of a formal learning environment. Proceedings of the $8^{\text {th }}$ IEEE international conference on advanced learning technologies: 529-533 
Ngonidzashe, Z. (2013). Challenges and perceptions towards use of social media in higher education in Zimbabwe: a learners' perspective. International Journal of Scientific \& Engineering Research, 4(5), 242-249.

Nwangwa, K. C., Yonlonfoun, E., \& Omotere, T. (2014). Undergraduates and their use of social media: Assessing influence on research skills. Universal Journal of Educational Research, 2(6), 446-453.

Parajuli, R., \& Doneys, P. (2017). Exploring the role of telemedicine in improving access to healthcare services by women and girls in rural Nepal. Telematics and Informatics, 34(7), 1166-1176.

Park, S. Y. (2009). An analysis of the technology acceptance model in understanding university students' behavioural intention to use e-learning. Journal of Educational Technology \& Society, 12(3), 150.

Poushter, J., Bell, J., \& Oates, R. (2015). The Internet is seen as a positive influence on education but negative on morality in emerging and developing nations. Washington, DC: Pew Research Center.

Prensky, M. (2001). Digital natives, digital immigrants. On the Horizon, S(5), 1-6.

Roebuck, D., Siha, S., \& Bell, R. L. (2013). Faculty usage of social media and mobile devices: analysis of advantages and concerns. Interdisciplinary Journal of E-Learning and Learning Objects, 9, 171.

Selwyn, N. (2009). Face working: Exploring Students' Education-Related Use of "Facebook". Learning, Media and Technology, 34 (2), 157-174.

Selwyn, N. (2012). Social media in higher education. The Europa world of learning, 1-10.

Shadrach, I. (2016). Screen time risks awareness and perception among undergraduate students in Northeast, Nigeria. (A work submitted to Postgraduate Studies Unit, Mass Communication Department, Nnamdi Azikiwe University, Awka, In Partial Fulfillment of the requirements For the Course Quantitative Research Method (MAC 841).

Shen, J., \& Eder, L. B. (2009). Intentions to Use Virtual Worlds for Education. Journal of Information Systems Education, 20 (2), 225-234.

Smith, S. D., Salaway, G., \& Caruso, J. B. (2009). The ECAR study of undergraduate students and information technology, 2009—key findings. http://www.csplacement.com/downloads/ECARITSkliisstudy.pdf

Stake, R. E. (2013). Multiple case study analysis. Guilford Press.

Stanciu, A., \& ALECA, O. (2012). Social networking as an alternative environment for education. Accounting and Management Information Systems, 11(1), 56.

Tamirat, K., \& Molly, T. M. (2014). Students use social networking sites and their perceptions about the effects of the use: The Case of Selected Adama Preparatory Schools (Doctoral dissertation, Haramaya University).

Venkatesh, V., \& Davis, F. D. (2000). A theoretical extension of the technology acceptance model: Four longitudinal field studies. Management Science, 46(2), 186-204.

Wang, Y., \& Braman, J. (2009). Extending the Classroom through Second Life. Journal of Information Systems Education, 20 (2), 235.

Wankel, C. (2009). Management education using social media. Organization Management Journal, 6(4), 251-262.

Wu, Y. L., Tao, Y. H., \& Yang, P. C. (2008). The use of the unified theory of acceptance and use of technology to confer the behavioural model of $3 \mathrm{G}$ mobile telecommunication users. Journal of Statistics and Management Systems, 11(5), 919-949. 